proxies of climatic variation from the same sites inferred from $\delta^{18} \mathrm{O}$ data reveal complex community responses to climatic fluctuations. For example, vegetation at one of Yu's sites (Crawford Lake, Ontario) had begun to shift to spruce forest by $\sim 500$ years after the Bølling-Allerød warming phase $(\sim 12700$ years $\mathrm{Bp})$. However, there was a rapid increase in herb pollen percentages at the onset of the Younger Dryas event that was indicative of differential responses among the arboreal and herbaceous components. With the onset of rapid warming at the termination of the Younger Dryas event, however, there is a dramatic change in vegetation that is evident from Yu's data: spruce-dominated forests shifted to pine-dominated forests within a span of $\sim 100$ years or less, spurred by the onset of Holocene warming.

Such variability in the rate and nature of vegetation responses to climatic events might reflect the importance of factors such as baseline climatic conditions at various sites, biological inertia in the process of succession, facilitation of invasion by some species through the earlier presence of nitrogen fixers, and the proximity of refugia from which species can migrate to recently exposed sites. This last factor might be of particular relevance to Yu's results for post-glacial expansion of spruce, because independent plant macrofossil data indicate that spruce occurred at the very edge of the ice sheet during the Last Glacial Maximum, $\sim 18000 \pm 1500$ years Bp [14], and spruce migration rates have been estimated to vary between 0.05 and $>1 \mathrm{kmy}^{-1}$, with a median rate of $0.10 \mathrm{~km} \mathrm{y}^{-1}[15,16]$.

The importance of these two studies lies in their ability to put a finger on just how quickly plant communities appear to have responded, and might continue to respond, to climate change. The beauty of the approaches taken by Williamset al. [4] and Yu [5] lies in the fact that, not only do they confirm earlier theoretical predictions of the potential rapidity with which plant community composition might respond to abrupt climate changes, but they also complement the many studies of both plant and animal response to climatic events, variability and change that focus on spatial fluxes (e.g. [3]). The information provided by this pair of new papers, and the others that they will no doubt spawn, will prove valuable in future efforts to model the responses of plant and animal species to predicted climate change. In particular, the quantitative insights provided by these papers might facilitate the mechanistic modeling of climate change-related geographical range shifts and community dynamics at higher trophic levels, including large herbivores that survived the Pleistocene-Holocene transition [11].

\section{Acknowledgements}

I would like to thank David Post, Jack Williams and two anonymous referees for helpful comments and discussions that greatly improved this article.

\section{References}

1 Guthrie, R.D. (2000) Origin and causes of the mammoth steppe: a story of cloud cover, woolly mammal tooth pits, buckles, and inside-out Beringia. Quat. Sci. Rev. 20, 549-574

2 Guthrie, R.D. (1996) Four late Pleistocene large mammal localities in interior Alaska. In American Beginnings: The Prehistory and Palaeoecology of Beringia (West, F.H., ed.), pp. 119-129, University of Chicago Press

3 Parmesan, C. and Yohe, G. (2003) A globally coherent fingerprint of climate change impacts across natural systems. Nature 421, 37-42

4 Williams, J.W. et al. (2002) Rapid and widespread vegetation response to past climate change in the North Atlantic region. Geology 30, 971-974

$5 \mathrm{Yu}, \mathrm{Z}$. (2003) Late Quaternary dynamics of tundra and forest vegetation in the southern Niagara Escarpment, Ontario. New Phytol. 157,365-390

6 Alley, R.B. (2000) Ice-core evidence of abrupt climate changes. Proc. Natl. Acad. Sci. U. S. A. 97, 1331-1334

7 Walther, G-R. et al. (2002) Ecological responses to recent climate change. Nature 416, 389-395

8 Lischke, H. et al. (2002) Untangling a Holocene pollen record with forest model simulations and independent climate data. Ecol. Model. 150,1-21

9 Overpeck, J.T. et al. (1991) Potential magnitude of future vegetation change in eastern North America: comparisons with the past. Science $254,692-695$

10 Jackson, S.T. and Weng, C. (1999) Late Quaternary extinction of a tree species in eastern North America. Proc. Natl. Acad. Sci. U. S. A. 96, 13847-13852

11 Schmitz, O.J. et al. Ecosystem responses to global climate change: moving beyond color mapping. Bioscience (in press)

12 Peterson, R.O. et al. (1984) Wolves, moose, and the allometry of population cycles. Science $224,1350-1352$

13 Terasme, J. and Matthews, H.L. (1980) Late Wisconsin white spruce (Picea glauca (Moench) Voss) at Brampton, Ontario. Can. J. Earth Sci. $17,1087-1095$

14 Jackson, S.T. et al. (2000) Vegetation and environment in Eastern North America during the last glacial maximum. Quat. Sci. Rev. 19, 489-508

15 Clark, J.S. et al. (1998) Reid's paradox of rapid plant migration: dispersal theory and interpretation of paleoecological records. Bioscience 48, 13-24

16 Ritchie, J.C. and MacDonald, G.M. (1986) The patterns of post-glacial spread of white spruce. J. Biogeog. 13, 527-540

17 Dansgaard, W. et al. (1989) The abrupt termination of the Younger Dryas climate event. Nature 339, 532-534

18 Alley, R.B. et al. (1993) Abrupt increase in Greenland snow accumulation at the end of the Younger Dryas event. Nature 362, 627-629

19 Alley, R.B. et al. (2003) Abrupt climate change. Science 299, 2005-2010

\title{
Controlling the false discovery rate in ecological research
}

\section{Luis V. García}

\author{
Departamento de Geoecología, IRNAS-CSIC. P.O. Box 1052, E41080-Sevilla, Spain
}

A controversial question when analyzing outcomes of ecological research has been whether the increase of type I

Corresponding author: Luis V. García (ventura@cica.es). error under repeated testing should be taken into account for evaluating the scientific soundness of the results [1-3]. The traditional strong control of the familywise error rate (FWER) (i.e. the probability of obtaining one or more 
spurious rejections) at the $5 \%$ level becomes prohibitive in studies involving dozens (or hundreds) of repeated tests. As the research becomes more detailed - and the possibility of getting a higher number of variables increases - the problem intensifies, arriving at the apparent paradox that the more detailed the research, the less the probability of obtaining any significant result [3].

\section{The false discovery rate}

Benjamini and Hochberg [4] realized that, in studies where a large number of repeated test are performed, the researcher might be more interested in controlling the proportion of 'false discoveries' (i.e. the proportion of erroneously rejected null hypotheses) than in the probability of obtaining even one spurious rejection. Because controlling false discovery rate (FDR) allows for increased power in large series of repeated tests, this procedure is rapidly becoming established in many areas where studies involving many repeated tests are frequently performed [5,9,10]. Furthermore, the original FDR approach has been the object of successive improvements in recent years [5-8].

Because controlling FDR means a compromise between the application of a well founded statistical principle (alphainflation under repeated tests) and the need to avoid the unacceptable loss of power implied by strong control of the FWER in large test tables, it might be a solution for many ecological studies involving highly repeated testing on the same sampling units (as in monitoring), simultaneous tests on many biological or environmental variables, or the reanalysis of many published data sets.

Although most general-purpose statistical programs do not yet include routines for controlling FDR, several authors involved in FDR findings offer public-domain software on their web sites (http://www.math.tau.ac.il/ $\sim$ roee/FDR_Downloads2.htm; http://faculty.washington. edu/ jstorey/qvalue/; http://www.sph.umich.edu/ nichols/ FDR/index.html).

\section{References}

1 Rice, W.R. (1989) Analyzing tables of statistical tests. Evolution 43, $223-225$

2 Cabin, R.J. and Mitchell, R.J. (2000) To Bonferroni or not to Bonferroni: when and how are the questions. ESA Bull. 81, 246-248

3 Moran, M.D. (2003) Arguments for rejecting the sequential Bonferroni in ecological studies. Oikos 100, 403-405

4 Benjamini, Y. and Hochberg, Y. (1995) Controlling the false discovery rate: a practical and powerful approach to multiple testing. J. R. Stat. Soc. Ser. B 57, 289-300

5 Reiner, A. et al. (2003) Identifying differential genes using false discovery rate controlling procedures. Bioinformatics 19 $368-375$

6 Yekutieli, D. and Benjamini, Y. (1999) Resampling-based false discovery rate controlling multiple test procedures for correlated test statistics. J. Stat. Plan. Infer. 82, 171-196

7 Storey, J.D. (2002) A direct approach to false discovery rates. J. R. Stat. Soc. Ser. B 64, 479-498

8 Genovese, C.R. and Wasserman, L. (2002) Operating characteristics and extensions of the false discovery rate procedure. J. R. Stat. Soc. Ser. $B$ 64, 499-517

9 Hopkins, A.M. et al. (2002) A new source detection algorithm using the false discovery rate. Astronom. J. 123, 1086-1094

10 Genovese, C.R. et al. (2002) Thresholding of statistical maps in functional neuroimaging using the false discovery rate. Neuroimage $15,772-786$

0169-5347/\$ - see front matter (C) 2003 Elsevier Ltd. All rights reserved. doi:10.1016/j.tree.2003.08.011

\section{Phenotypic flexibility}

\section{Brian L. Bayne ${ }^{1}$ and Pieter J. C. Honkoop ${ }^{2}$}

${ }^{1}$ Centre for Research on Ecological Impacts of Coastal Cities, Marine Ecology Labs, A11, University of Sydney, NSW 2006, Australia ${ }^{2}$ Royal Netherlands Institute for Sea Research, Department of Marine Ecology and Evolution, PO Box 59, 1790 AB Den Burg, The Netherlands

In a recent paper in TREE, Piersma and Drent [1] argue that phenotypic plasticity is a significant factor in understanding animal adaptation. We agree with this thesis and their call for more 'appropriate phenotypic experimentation, comparison and integration'. We wish, however, to correct their use of our study [2] of the changes in the sizes of the feeding organs of the oyster Crassostrea gigas.

In interpreting our observations on seasonal variability in the feeding organs of the oyster (viz. the gill:palp ratio), Piersma and Drent superimposed on our data (see their Figure 2) 'an algal bloom period' to suggest that the morphological changes are 'driven by changes in food availability'. Although not cited, these data for an 'algal bloom period' were taken from a different study [3] of the continental shelf off the New South Wales (NSW) coast of Australia. Our experiments were done within the Port

Corresponding author: Brian L. Bayne (baynebrian@hotmail.com).
Stephens estuary, NSW. Seasonal changes in phytoplankton production off shore are unlikely to determine the food environment for oysters within this estuary.

Independently of the Honkoop et al. study, we have measured the particulate food available to the oysters within the Port Stephens estuary [4]. The relationship between food and changes in the feeding organs is complex. In general, an increase in the gill:palp ratio between October and March coincides with a decline in dietary quality (i.e. the organic content of the food particles), rather than an increase in dietary quantity. Later in the year, a decline in food quantity might contribute to a reduction in the gill:palp ratio. Such relationships are consistent with the mechanics offeeding in oysters [5,6] (Figure 1).

Any link between changes in the relative sizes of gills and palps in oysters and seasonal changes in their food environment remains to be formally tested. We believe, nevertheless, that such a study is likely to support the basic 